\title{
Plano Diretor e Ordenamento Territorial: uma análise do espaço urbano de Natal
}

\section{Master Plan and Territorial Planning: an analysis of Natal urban space}

Eugênia Maria Dantas - Doutora; professora do Programa de Pós-Graduação em Geografia da Universidade Federal do Rio Grande do Norte (UFRN), Natal-RN. E-mail: eugeniadantas@yahoo.com.br

Adriano Lima Troleis - Doutor; professor do Programa de Pós-Graduação em Geografia da Universidade Federal do Rio Grande do Norte (UFRN), Natal-RN. E-mail: adrianotroleis@gmail.com

Ione Rodrigues Diniz Morais - Doutora; professora do Programa de Pós-Graduação em Geografia da Universidade Federal do Rio Grande do Norte (UFRN), Natal-RN. E-mail: ionerdm@yahoo.com.br

\section{Resumo}

Este trabalho discute o ordenamento do espaço urbano de Natal/RN/Brasil, a partir do Plano Diretor de Desenvolvimento Urbano que evidencia a territorialização em Zonas de Proteção Ambiental. Metodologicamente, o trabalho está embasado em referências importantes para problematizar o espaço citadino, levando em consideração os entraves e as articulações que se projetam a partir de decisões, ações e intervenções planejadas ou não e em pesquisa documental, sobremaneira o Plano Diretor de Desenvolvimento Urbano de Natal, o qual estabelece as diretrizes para o uso e ocupação do solo. A análise da ambiência urbana de Natal permite inferir que a territorialização, a partir do viés ambiental, rebate na dinâmica da cidade, impulsionando a ambiguidade entre conservar e modificar a paisagem; possibilita enxergar os matizes e as matrizes que envolvem sua dinâmica, deixando sobressair os limites e potencialidades do Plano Diretor como instrumento de ordenamento territorial.

\section{Palavras-chave}

Espaço urbano. Plano diretor. Ordenamento territorial. Zona de Proteção Ambiental.

\begin{abstract}
This work discusses the planning of Natal/ $\mathrm{RN} /$ Brazil urban space, from the Urban Development Master Plan, which highlights the territorialization in Environmental Protection Zones, Social Interest Areas and Template Control Areas. Methodologically, the work is based in important references to problematize city space, taking into account barriers and articulations that project themselves from decisions, actions and planned interventions or not, and documentary research, especially Natal Urban Development Master Plan, which establishes guidelines for the use and occupation of land. The analysis of Natal urban ambience allows to infer that the territorialization from environmental bias has consequences in the dynamics of the city, boosting the ambiguity between conserve and modify the landscape, letting stand out Master Plan limits and potentialities as a tool for territorial planning.
\end{abstract}

\section{Keywords}

Urban space. Master Plan. Territorial Planning. Environmental Protection Zones. 


\section{URBANIZAÇÃO BRASILEIRA}

O cenário urbano atual tem se apresentado bastante complexo, desafiando moradores, planejadores e gestores, dentre outros que precisam criar estratégias de convivência com um ambiente mutante e exigente quanto aos seus processos de organização. De acordo com Ana Fani Alessandri Carlos (2007):

A cidade, enquanto construção humana é um produto histórico-social e nesta dimensão aparece como trabalho materializado, acumulado ao longo do processo histórico de uma série de gerações. Expressão e significação da vida humana, obra e produto, processo histórico cumulativo, a cidade contém e revela ações passadas, ao mesmo tempo em que o futuro, que se constrói nas tramas do presente - o que nos coloca diante da impossibilidade de pensar a cidade separada da sociedade e do momento histórico analisado (CARLOS, 2007, p. 11).

Nessa perspectiva, enveredarmos pela análise da cidade e encontramos nas sucessivas reorganizações espaciais a recriação da paisagem alicerçada nos códigos que combinam a permanência e a mudança, o passado e o presente, os sinais do ser e do acontecer no tempo e no espaço.

$\mathrm{Na}$ análise da dimensão urbana da natureza empreendida por Yuri Simonini e Angela Lúcia Ferreira (2013, p. 1) evidencia-se uma complexa relação entre o homem e o meio ambiente, na transformação territorial através da exploração dos recursos naturais, gerando paisagens que apresentam uma natureza artificializada pela incorporação de trabalho e técnica. Essa paisagem revela uma urbanidade que combina, de forma heterogênea, interesses diversos, configurando-se como um tecido "fragmentado, articulado, reflexo, condicionante social, cheio de símbolos e campo de lutas - é um produto social, resultado de ações acumuladas através do tempo, e engendradas por agentes que produzem e consomem espaço" (SIMONINI; FERREIRA, 2013, p.11). Nesse sentido, admite-se que a organização da ambiência urbana está envolta por processos que delimitam os seus diferentes usos e ocupações, configurando uma malha que delineia limites e fronteiras territoriais.

Ademais, o espaço urbano apresenta-se enredado em questões de ordem política, econômica, cultural e ambiental, que exigem planejamento e intervenções, por vezes urgentes, inovadoras e/ou resolutivas. Tais questões estão articuladas à dinâmica citadina, marcada por políticas relacionadas com diferentes situações como urbanização de áreas, regularização de terrenos e habitações, remoção de populações, dentre outras. Desse modo, as políticas urbanas repercutem diretamente sobre a vida da população e na valorização do espaço. 
Do ponto de vista do mercado imobiliário, os recortes da cidade que são alvo de políticas de infraestrutura, como abastecimento de água, esgotamento sanitário, coleta de lixo, iluminação, pavimentação, entre outros serviços, tendem a se valorizar, enquanto aqueles situados, em geral, na periferia, e que são desprovidos de tais serviços urbanos, apresentam tendência à desvalorização. Nesse contexto, as questões vinculadas ao uso e à ocupação do solo urbano assumem expressão e densidade.

No Brasil, o processo de urbanização diretamente articulado ao projeto de modernização via industrialização, difundido no âmbito do sistema capitalista, acelerou-se a partir da década de 1950. Todavia, esse processo não atingiu o território nacional de modo igualitário, apresentando diferentes níveis de efetivação, o que levou Milton Santos (1989, p. 153) a afirmar que, "entre zonas de densidade elevadas, aparecem 'desertos urbanos', que nem sempre correspondem às zonas menos densamente povoadas". Assim, no decurso da urbanização brasileira, vivenciou-se uma intensa migração rural-urbana e, por conseguinte, uma significativa concentração de pessoas nas cidades, conforme podemos identificar na Tabela 1.

Tabela 1 - População Total e Urbana do Brasil - 1940/2010

\begin{tabular}{|r|r|r|r|}
\hline \multirow{2}{*}{ Anos } & \multicolumn{2}{|c|}{ População } & \multicolumn{2}{c|}{$\begin{array}{c}\text { Índice de } \\
\text { Urbanização (\%) }\end{array}$} \\
\cline { 2 - 3 } & \multicolumn{1}{|c|}{ Total } & Urbana & 31,23 \\
\hline 1940 & 41.326 .315 & 12.880 .182 & 36,16 \\
\hline 1950 & 51.994 .397 & 18.782 .891 & 44,60 \\
\hline 1960 & 70.191 .370 & 31.303 .034 & 55,92 \\
\hline 1970 & 93.139 .037 & 52.084 .984 & 67,59 \\
\hline 1980 & 119.002 .706 & 80.436 .409 & 75,59 \\
\hline 1991 & 146.825 .475 & 110.990 .990 & 81,25 \\
\hline 2000 & 169.799 .170 & 137.953 .959 & 84,36 \\
\hline 2010 & 190.755 .799 & 160.925 .792 & \\
\hline
\end{tabular}

Fonte: Censos demográficos (IBGE, 1940/2010). Disponível em: <www.ibge.gov.br>. Acesso em: 23 maio 2010.

De acordo com as informações apresentadas, em 1940, a população urbana do Brasil correspondia a 31,23\% da população total. Assumindo uma perspectiva crescente, em 2010 o índice de urbanização atingiu 84,36\%. Portanto, entre os anos de 1940 e 2010, no total do contingente brasileiro, a participação da população urbana cresceu significativamente, sendo importante ressaltar que o Censo de 1970 já havia revelado a predominância de habitantes em ambientes urbanos. 
A avaliação desse cenário, considerando o número de cidades e a população urbana, permite inferir que, embora apresente um número significativo de pequenas cidades, é nas grandes cidades que se concentra parcela expressiva da população. As estatísticas são elucidativas: em 2010, das 5.565 cidades brasileiras, $5.132(92,21 \%)$ possuíam até 50.000 habitantes, enquanto $533(7,78 \%)$ possuíam mais de 50.000 moradores. Além disso, do total de 143.792 .645 residentes urbanos, 44.983.803 (31,29\%) moravam em cidades com até 50.000 habitantes, enquanto 98.808.842 (68,72\%) residiam em cidades com mais de 50.000 habitantes (IBGE, 2010). Ao longo dos anos, a expressiva e contínua concentração de pessoas nas cidades, sem que estas fossem alvo de planejamento e gestão eficientes, gerou uma série de demandas e problemas de diferentes ordens (sociais, ambientais, econômicos, entre outros), em escalas de abrangência diversificadas.

$\mathrm{Na}$ década de 1990, a acentuação dos problemas urbanos relacionados à carência e/ou precariedade da infraestrutura, a ocupação desordenada do solo, os impactos ambientais, dentre outros, suscitou a necessidade de se desenvolverem estratégias de planejamento do uso e ocupação do espaço citadino.

Nesse ínterim, foram aprimorados estudos e experiências que focalizaram o planejamento e a gestão como ferramentas para a promoção do desenvolvimento urbano no país.

\section{PLANEJAMENTO, GESTÃO E DESENVOLVIMENTO URBANOS}

A vida na cidade pressupõe um nível de organização social que torna imprescindível a atuação do poder público e, no âmbito desta, avulta a necessidade de planejar para se atingir estratégias eficientes de gestão do espaço urbano.

Segundo Marcelo Lopes de Souza (2011, p. 46), planejamento e gestão não são termos intercambiáveis, por possuírem referenciais temporais distintos e se referirem a diferentes tipos de atividades. O planejamento sempre remete ao futuro, no sentido de prever a evolução de um fenômeno, simular os desdobramentos de um processo, objetivando precaver-se contra prováveis problemas ou encontrar estratégias para usufruir de prováveis benefícios. A gestão, por sua vez, remete-se ao presente, significando administrar os recursos disponíveis levando-se em consideração as necessidades imediatas. Planejamento e gestão são distintos e complementares, na perspectiva de se empreender ações previamente refletidas.

Planejar e gerir realizam-se em temporalidades distintas. A primeira requer uma visão de futuro, de imaginação e de projeção. A segunda constitui-se pela necessidade, pela premência do presente e das condições disponíveis. É na 
interseção entre necessidade e projeção que se efetiva a eficácia e a eficiência desses dois dispositivos, na medida em que se pode atualizar, reorganizar ou refazer o que foi projetado à luz do que é possível. Já o cruzamento entre planejamento e gestão conduz à possibilidade de refinamento e aperfeiçoamento desses dispositivos, tornando-os mais flexíveis e adequados às mudanças sociais.

No que se refere ao planejamento e à gestão urbanos, torna-se relevante considerar a cidade como um organismo vivo, complexo e mutável, assumindose a tarefa de promover as diretrizes e estratégias que favoreçam o seu desenvolvimento. Mas o que se deve entender por desenvolvimento urbano em uma sociedade que apresenta tantas diferenças e desigualdades?

De acordo com Marcelo Lopes de Souza (2011, p. 62), a concepção de desenvolvimento urbano está associada ao desenvolvimento socioespacial, sendo este entendido como um processo que ocorre quando se constata "uma melhoria na qualidade de vida e um aumento da justiça social". Neste sentido, a melhoria da qualidade de vida corresponde à crescente satisfação das necessidades - tanto básicas quanto não básicas; tanto materiais quanto imateriais - de uma parcela cada vez maior da população. Quanto à questão do aumento da justiça social, trata-se de uma discussão mais complexa, pois esbarra na multiplicidade de concepções.

Nessa perspectiva, o desenvolvimento urbano é uma pretensão que deve se realizar a partir da intersecção entre os diferentes segmentos sociais, levando-se em conta o contexto atual e os cenários futuros. Trata-se de construir projeções em que se combinam elementos de natureza econômica, cultural, social e ambiental em diferentes escalas - local, regional, nacional e mundial. A formatação desses cenários de desenvolvimento reflete as condições materiais e imateriais existentes, devendo considerar os diferentes níveis de relação e/ou dependência espacial.

Além disso, o desenvolvimento urbano articula programas e estratégias, associando o existente ao que se deseja atingir, a partir da indução de determinadas ações, estando aberto à inovação e a redirecionamentos sempre que necessário. A consciência da necessidade cotidiana que induz ao fazer imediato combina-se à criação de possibilidades e inovações. Dessa feita, o desenvolvimento urbano, ancorado no desejo de "alterar positivamente" à realidade, utiliza-se do espaço como fonte de recursos e ambiente no qual o indivíduo e a sociedade realizam os seus mais diversos sonhos, de natureza material e simbólica.

Assim, torna-se fundamental a atuação do poder público no sentido de decidir, planejar e executar políticas que possibilitem a realização dessa 
perspectiva de desenvolvimento. Nesse cenário, emergem as políticas públicas enquanto instrumentos legais de planejamento e gestão urbanos.

No Brasil, as questões vinculadas à política urbana foram contempladas na Constituição de 1988, que fixou a exigência de elaboração de Plano Diretor para os municípios com população urbana acima dos 20 mil habitantes; os integrantes de regiões metropolitanas ou aglomerações urbanas de áreas de especial interesse turístico; e os municípios inseridos em áreas sob a influência de empreendimentos ou com significativo impacto ambiental.

Nesse contexto, o Governo Federal, por meio da Lei n ${ }^{\circ} 10.257$, de 10 de julho de 2001, regulamentou os artigos 182 e 183 da Constituição Federal, estabelecendo as diretrizes gerais da política urbana. A referida Lei, também denominada Estatuto da Cidade, estabelece parâmetros, princípios, objetivos, diretrizes de ação e instrumentos que podem ser utilizados pelo poder público municipal para assegurar a gestão urbana a partir de dispositivos normativos e legais.

Numa perspectiva inovadora, esse Estatuto pressupõe pensar a gestão urbana de maneira democrática e o espaço para a coletividade, a partir da interseção entre crescimento econômico e promoção social, compatíveis com uma política de conservação do meio ambiente e dos recursos naturais. Assim, de acordo com José Borzacchielo Silva (2003, p. 33), a política urbana constitui um arranjo que combina as diferentes esferas da ambiência citadina, como transportes, habitação, patrimônio histórico, áreas de preservação ambiental, dentre outras.

Dentre as inovações de que trata o Estatuto da Cidade, destaca-se o Plano Diretor - instrumento básico que regulamenta o planejamento e o desenvolvimento urbanos e deve assegurar o atendimento das necessidades dos cidadãos quanto à qualidade de vida, à justiça social e ao desenvolvimento das atividades econômicas. Seguindo as diretrizes normativas, os planos diretores foram elaborados por meio de um processo democrático que envolveu o poder público e os representantes da sociedade civil organizada.

Segundo Moacyr Moojen Marques (1986), um plano diretor, como instrumento de política pública, deve conter diretrizes; adequar conceitos; estabelecer padrões e estruturas adequados às condições da cidade e contribuir com as mudanças de natureza socioeconômica ou de valores urbanísticos culturais e ambientais. Nesse sentido, tais planos tornam-se fundamentais às permanências e modificações da paisagem urbana, podendo restringir ou induzir o uso e a ocupação do solo citadino. 
Desse modo, pode-se inferir que, cabe ao poder público a tarefa de produzir espaço tecnicamente possível de ocupação, por meio de obras de saneamento básico, fornecimento de energia, construção de moradias e vias de acesso, entre outras, tanto para fins residenciais quanto empresariais. Todavia, segundo Henrique Rattner (2001), as decisões sobre a organização do espaço e da vida social e cultural ultrapassam a problemática e a competência técnicoinstrumental dos planejadores e tecnocratas, pois exigem diálogo, comunicação e interação entre o poder público e a sociedade.

Não obstante, os avanços vivenciados no país em termos de normatizações e práxis que envolvem o planejamento e a gestão urbanos, torna-se importante reconhecer que ainda há muito a ser conquistado e construído. Considerando a predominância de posturas políticas comprometidas com interesses de grupos econômicos hegemônicos, pensar a cidade e as políticas públicas para todos os cidadãos tem sido um enorme desafio para os gestores que almejam a construção de um desenvolvimento socioespacial, conforme definido por Marcelo Lopes de Souza (2011, p. 72), que se traduza em melhoria da qualidade de vida e em justiça social.

\section{ORDENAMENTO TERRITORIAL URBANO: A CIDADE DE NATAL}

$\mathrm{Na}$ perspectiva de refletir sobre urbanização, planejamento, gestão e desenvolvimento urbanos, elegeu-se como referência empírica de análise a cidade de Natal, localizada no estado do Rio Grande do Norte, na Região Nordeste do Brasil.

Natal e o seu entorno configuram-se como o espaço geográfico de maior atração populacional e concentração demográfica no âmbito estadual, o que repercute em demandas sociais e problemas urbanos. Os dados demográficos são importantes para se entender esse processo. Em 1991, a área que corresponde atualmente à Região Metropolitana de Natal possuía 892.134 habitantes, dos quais 606.887 eram residentes em Natal (68\%). Em 2010, essa mesma região passou a contabilizar 1.351.004 habitantes, sendo 803.739 habitantes de Natal (59\%). No início dos anos 2000, Natal já vivenciava o processo de conurbação com a cidade de Parnamirim e a extrapolação de suas franjas, adentrando os territórios de São Gonçalo do Amarante e Extremoz, o que evidenciava um novo arranjo territorial para além de suas fronteiras, acentuando o papel da cidade sobre o seu entorno. A Figura 1 apresenta a Região Metropolitana de Natal, seus municípios e respectivas populações. 
Figura 1 - Região Metropolitana de Natal.
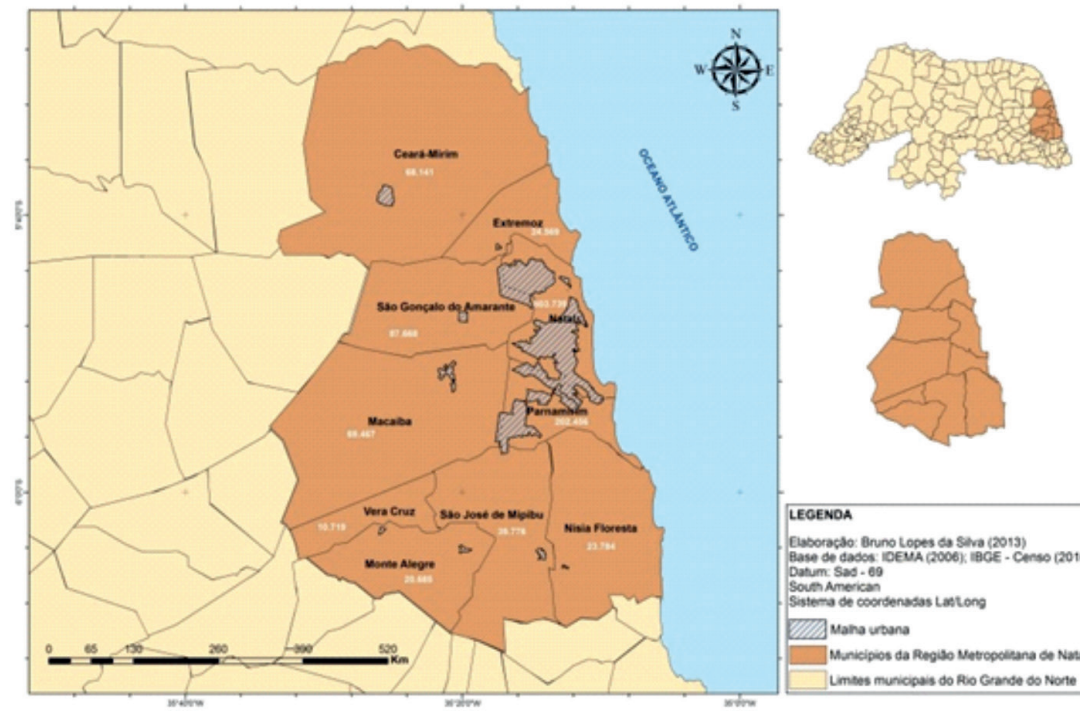

Fonte: IDEMA (2006) e IBGE (2010). Adaptação dos autores.

Nesse contexto, o município de Natal constitui-se uma realidade espacial que, para fins de gestão, apresenta-se fragmentado em quatro regiões administrativas: Norte, Sul, Leste e Oeste - que abrangem 36 bairros, conforme pode ser visualizado na Figura 2.

Figura 2 - Regiões administrativas de Natal.

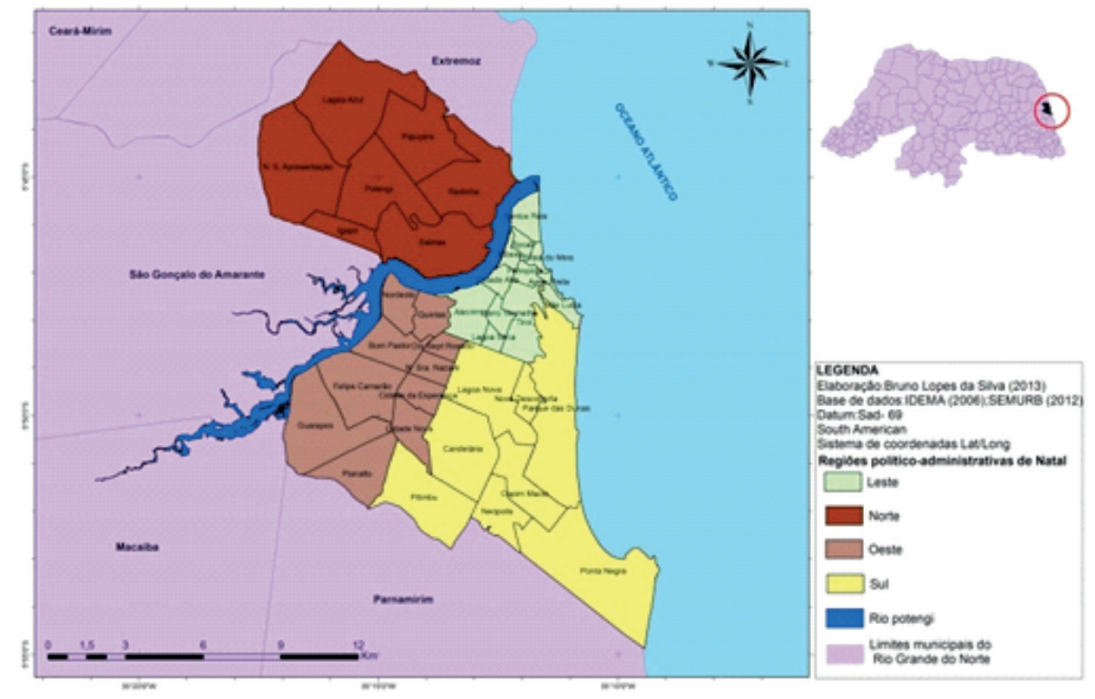

Fonte: IDEMA (2006) e SEMURB (2012). Adaptação dos autores. 
Considerando as regiões administrativas e a ambiência urbana, o ordenamento territorial de Natal foi importante para delinear as diretrizes para o Plano Diretor do município. Neste sentido, levou-se em consideração as necessidades socioeconômicas e as características naturais que configuram a sua paisagem, como a existência de estuários, restingas, dunas, recifes, praias, planícies, manguezais, Mata Atlântica, rios, lagoas e águas subterrâneas.

Desta feita, em 2007 ocorreu o processo de reformulação do Plano Diretor, no qual foram consideradas como estratégicas as questões de ordem ambiental para refletir sobre o território, o que resultou em um macrozoneamento, com destaque para as Zonas de Proteção Ambiental, definidas como áreas nas quais as características do meio físico restringem o uso e a ocupação do solo urbano, visando à proteção, à manutenção e à recuperação dos aspectos paisagísticos, históricos, arqueológicos e científicos.

Na construção, aprovação e implementação do Plano ficaram evidenciados os mecanismos utilizados, as dificuldades encontradas, os diferentes interesses que envolvem o uso e a ocupação do solo. Para Marise Costa Duarte (2011, p. 361), a construção do Plano Diretor de 2007 foi caracterizada não só pela participação popular, mas também por evidenciar "o processo de fragilização dos direitos que envolvem momentos de construção e modificação da legislação urbana".

Ainda segundo Marise Duarte (2011, p. 406), o plano introduz a função socioambiental da propriedade urbana definindo no artigo $5^{\circ}$ e seus incisos que a propriedade urbana deve atender a requisitos que envolvem não apenas interesses sociais, como também aqueles devem ser atrelados às condições de infraestrutura instaladas e às de natureza ambiental. Essa inovação apresenta reflexos territoriais, tendo em vista que o fracionamento do espaço também estava associado a aspectos relativos à manutenção e à preservação do ambiente. Dessa forma, o plano manteve o zoneamento macro, dividindo o território em zona adensável, de adensamento básico e de proteção ambiental. Em um nível mais específico, detalhou o uso e a ocupação do solo em Áreas de Controle de Gabarito, Áreas Especiais de Interesse Social, Áreas de Operação Urbana e Áreas non aedificanti. A existência dessas áreas faz emergir o meio ambiente como agente que secciona o espaço urbano, criando limites e fronteiras territoriais, com rebatimentos importantes para delimitar, definir, impedir ou permitir o uso do solo.

Nesse sentido, território da Cidade do Natal, de acordo com o Plano Diretor, possui 10 Zonas de Proteção Ambiental (ZPA) (Figura 3), ou seja, zonas nas quais as características do meio físico restringem o uso e a ocupação, visando à proteção, à manutenção e à recuperação dos aspectos ambientais, ecológicos, paisagísticos, históricos, arqueológicos, turísticos, culturais, arquitetônicos e científicos. 
Figura 3 - Zonas de Proteção Ambiental de Natal.

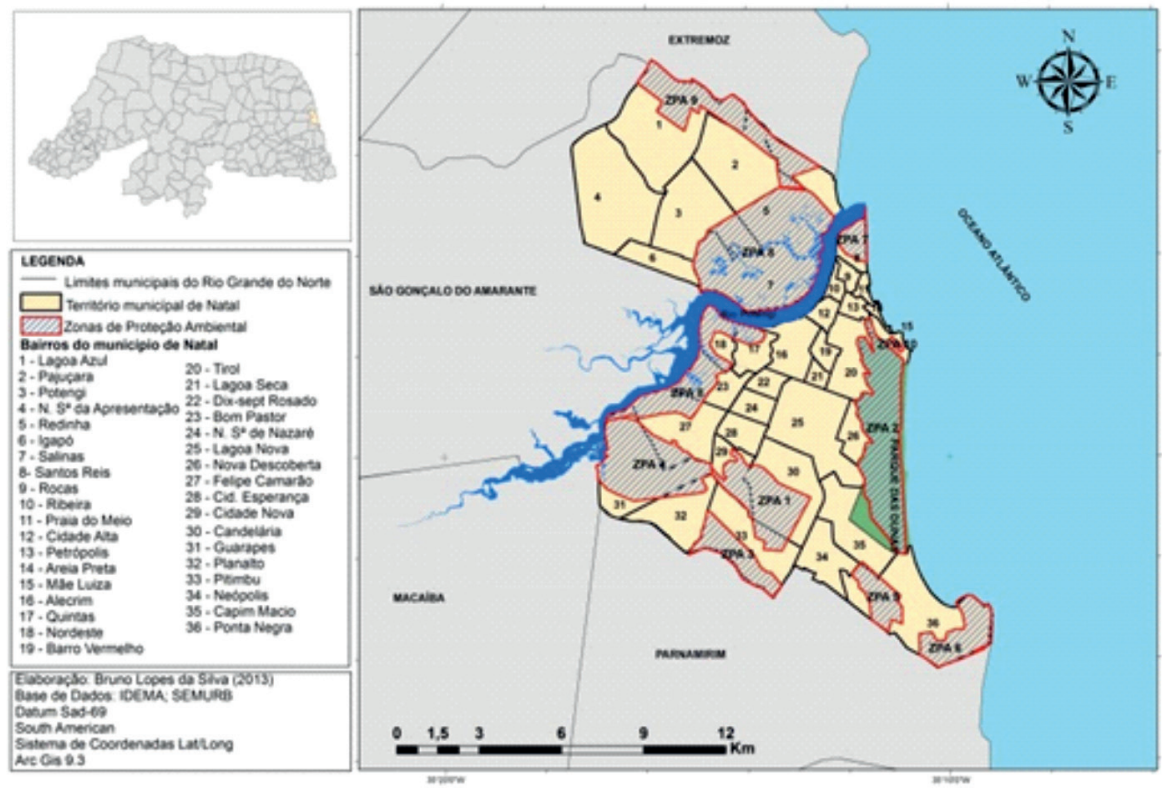

Fonte: IDEMA (2006) e SEMURB (2012). Adaptado pelos autores.

As ZPA estão localizadas em diferentes bairros da cidade e sua delimitação está incrustrada em áreas com variados níveis de adensamento populacional e múltiplas funções, como o uso para fins residenciais, comerciais e de serviços, dentre outros, conforme a identificação e respectivas funções das ZPA de Natal, apresentadas no Quadro 1.

Quadro - - Zonas de Proteção Ambiental da Cidade de Natal - 2010.

\begin{tabular}{|c|c|}
\hline IDENTIFICAÇÃO & FUNÇÃO \\
\hline $\begin{array}{l}\text { ZPA } 1 \text { - Campo Dunar dos bairros de } \\
\text { Pitimbu, Candelária e Cidade Nova, } \\
\text { regulamentada pela Lei Municipal n }{ }^{\circ} \\
\text { 04.664, de } 31 \text { de julho de } 1995 \text {. }\end{array}$ & $\begin{array}{l}\text { Recarga do aquífero subterrâneo que } \\
\text { garante a demanda de água potável da } \\
\text { cidade, além da proteção da fauna e flora } \\
\text { das dunas. }\end{array}$ \\
\hline $\begin{array}{l}\text { ZPA } 2 \text { - Paque Estadual das Dunas de } \\
\text { Natal e área contígua ao parque, Avenida } \\
\text { Engenheiro Roberto Freire e Rua Dr. } \\
\text { Solon de Miranda Galvão, regulamentado } \\
\text { pela Lei Estadual no } 7.237 \text {, de } 22 \text { de } \\
\text { novembro de } 1977 \text {. }\end{array}$ & $\begin{array}{l}\text { Atividades educativas, recreativas, } \\
\text { culturais e científicas. }\end{array}$ \\
\hline
\end{tabular}




\begin{tabular}{|c|c|}
\hline $\begin{array}{l}\text { ZPA } 3 \text { - Área entre o Rio Pitimbu e a } \\
\text { Avenida dos Caiacós (Cidade Satélite), } \\
\text { regulamentada pela Lei Municipal no } \\
05.273 \text {, de } 20 \text { de junho de } 2001 .\end{array}$ & $\begin{array}{l}\text { Suprimento de água doce para a Lagoa } \\
\text { do Jiqui, que abastece parte da cidade de } \\
\text { Natal. }\end{array}$ \\
\hline $\begin{array}{l}\text { ZPA } 4 \text { - Campo Dunar dos Bairros: } \\
\text { Guarapes e Planalto, regulamentada } \\
\text { pela Lei Municipal } n^{\circ} \text { 04.912, de } 19 \text { de } \\
\text { dezembro de } 1997 .\end{array}$ & Minimização do escoamento pluvial. \\
\hline $\begin{array}{l}\text { ZPA } 5 \text { - Ecossistema de dunas fixas e } \\
\text { lagoas do bairro de Ponta Negra (região } \\
\text { de Lagoinha) - regulamentada pela Lei } \\
\text { Municipal } n^{\circ} \text { 05.665, de } 21 \text { de junho de } \\
\text { 2004. }\end{array}$ & Recarga dos aquíferos. \\
\hline $\begin{array}{l}\text { ZPA } 6 \text { - Morro do Careca e dunas fixas } \\
\text { contínuas. }\end{array}$ & Atividade turística. \\
\hline $\begin{array}{l}\text { ZPA } 7 \text { - Forte dos Reis Magos e seu } \\
\text { entorno, tombado pelo Patrimônio } \\
\text { Histórico Nacional. }\end{array}$ & Atividade turística. \\
\hline $\begin{array}{l}\text { ZPA } 8 \text { - Ecossistema manguezal e } \\
\text { Estuário do Potengi/Jundiaí. }\end{array}$ & $\begin{array}{l}\text { Fonte de alimentação elocal de reprodução } \\
\text { de espécies da fauna marinha, refúgio } \\
\text { natural de peixes e crustáceos, propiciador } \\
\text { da indústria de pesca, atividades portuárias } \\
\text { e de recreação, fonte de sobrevivência } \\
\text { para as populações ribeirinhas. }\end{array}$ \\
\hline $\begin{array}{l}\text { ZPA } 9 \text { - Ecossistema de lagoas e dunas ao } \\
\text { longo do rio Doce. }\end{array}$ & $\begin{array}{l}\text { Perenização do rio Doce, recarga de } \\
\text { aquíferos e desenvolvimento de atividades } \\
\text { agrícolas. }\end{array}$ \\
\hline $\begin{array}{l}\text { ZPA } 10 \text { - Farol de Mãe Luiza e seu } \\
\text { entorno - encostas dunares adjacentes a } \\
\text { Via Costeira, entre o Farol de Mãe Luiza e } \\
\text { a Avenida João XXIII. }\end{array}$ & $\begin{array}{l}\text { Patrimônio histórico-cultural e área de } \\
\text { lazer. }\end{array}$ \\
\hline
\end{tabular}

Fonte: Anuário Natal 2011-2012. Natal: PMN/SEMURB, 2012.

De modo geral, as ZPA estão delimitadas para resguardar áreas que apresentam condições ambientais importantes para a manutenção do ecossistema urbano ou se constituem espaços de relevante valor cênico histórico. No entanto, a maioria delas está em espaços que já têm efetiva utilização socioeconômica, trazendo repercussões quanto à manutenção de áreas com uso restrito. Esse fato coloca em discussão o zoneamento ambiental que tem por objetivo a preservação, a melhoria e a recuperação da qualidade ambiental. 


\section{CONSIDERAÇÕES FINAIS}

No Brasil, o processo de urbanização acelerado legou às cidades a necessidade de conviver com cenários diversos, a partir de seus diferentes usos. Tem-se configurado situações em que os problemas decorrem de uma segunda natureza instalada e que requer compreender os seus limites; em outros contextos, a existência de uma natureza incrustada nas entranhas da segunda natureza torna-se um problema desafiante ao planejamento urbano. Pode-se considerar essa segunda situação como característica da realidade urbana de Natal, que requer um planejamento urbano e ordenamento territorial que levem em consideração interesses diferentes. Assim, o planejamento urbano tem no plano diretor um instrumento de ordenamento territorial na medida em que disciplina a ocupação e o uso dos diferentes espaços da cidade. A problematização desse instrumento no ordenamento urbano de Natal/RN/Brasil evidenciou processos de territorialização em que se destacam as ZPAs, que têm por objetivo a preservação, melhoria e recuperação da qualidade ambiental. Essas zonas estão inseridas em zonas já adensadas do espaço citadino, apresentando características diversas em termos físicos e de ocupação humana.

A delimitação das ZPA na cidade do Natal, por um lado constitui um avanço em termos de política socioambiental, que envolve a manutenção do ecossistema urbano e a conservação de paisagens de importante conteúdo histórico; por outro, revela a pressão exercida sobre esses espaços pelas populações que efetivamente o ocupam.

Nas entrelinhas do dilema urbano que envolve a pressão demográfica e econômica e a necessidades de conservação de ambientes naturais, destaca-se um cenário urbano que se transforma de maneira rápida, tendo em vista o contingente populacional existente e sua evidente tendência de crescimento. Nesse sentido, verifica-se um cenário no qual a população carece cada vez mais da sobreposição de objetos no espaço que garantam as condições mínimas de qualidade de vida mediante a ampliação e a criação de equipamentos urbanos. Essa sobreposição, por sua vez, pode se tornar um atrativo e intensificar a ocupação em uma área que tem uso restrito.

A existência de ZPA consiste em um elemento que tenciona o crescimento populacional sobre os espaços de proteção ambiental, requerendo cada vez mais o desenvolvimento de instrumentos que disciplinem o uso e a ocupação do espaço na perspectiva de evitar a apropriação indevida. Nesse aspecto, o ordenamento urbano definido no plano diretor pressupõe uma gestão pública que atente para a fiscalização e o controle do processo de produção do espaço urbano. Todavia, para a efetivação do referido plano, torna-se imprescindível que 
os gestores desenvolvam estratégias democráticas de participação popular nos debates e decisões, estabelecendo mecanismos de pactuação entre os diferentes segmentos e interesses sociais.

Nesse cenário, estabelece-se um desafio para a sociedade e a gestão do município de Natal no que se refere à construção de um desenvolvimento urbano que leve em consideração as necessidades sociais e os limites ambientais que existem em sua configuração espacial.

\section{REFERÊNCIAS}

CORRÊA, R. L. O espaço urbano. São Paulo: Ática, 1989.

CARLOS, A. F. A. A cidade. São Paulo: Contexto, 2007.

DUARTE, M. C. de S. Espaços especiais urbanos: desafios à efetivação dos direitos ao meio ambiente e à moradia. Rio de Janeiro: Observatório das Metrópoles, 2011.

IBGE-INSTITUTO BRASILEIRO DE GEOGRAFIA E ESTATÍSTICA. Censo demográfico 2010. Disponível em: <www.ibge.gov.br>. Acesso em: 4 set. 2014.

JEROEN, K.; ROSANA, D. O plano diretor participativo e a produção social do espaço. O caso de Santo André (São Paulo). Scripta Nova Revista Electrónica de Geografía Y Ciencias Sociales, Barcelona, v. 15, n. 382, 1 dic. 2011.

MARQUES, M. M. O plano diretor. Revista da Sociedade de Engenharia do Rio Grande do Sul, v. 1, n.12, p. 29-42, 1986.

NUNES, E. A Geografia física do Rio Grande do Norte. Natal: Imagem Gráfica, 2006.

PREFEITURA MUNICIPAL DE NATAL. Anuário Estatístico de Natal 2011-2012. Natal: SEMURB, 2012.

PREFEITURA MUNICIPAL DE NATAL. Ordenamento urbano de Natal: do Plano Polidrelli ao Plano Diretor 2007. Natal: SEMURB/Departamento de Informação, Pesquisa e Estatística, 2007.

RATTNER, H. A duração das cidades: sustentabilidade e risco nas políticas urbanas. In: ACSELRAD, H. (Org.). Sentidos da sustentabilidade urbana. Rio de Janeiro: DP\&A, 2001. p. 9-19.

SANTOS, M. A natureza do espaço: técnica e tempo, razão e emoção. São Paulo: Hucitec, 1996.

SANTOS, M. Manual de Geografia Urbana. Paulo: Hucitec, 1989.

SILVA, J. B. da. Estatuto da cidade versus estatuto de cidade - eis a questão. In: CARLOS, A. F. A.; LEMOS, A. I. G. (Org.). Dilemas urbanos: novas abordagens sobre a cidade. São Paulo: Contexto, 2003. p. 29-34. 
SIMONINI, Y.; FERREIRA, A. L. A dimensão urbana da natureza: considerações sobre a história ambiental. Biblio 3w, Barcelona, v. 18, n.1039, p. 1-27, ago. 2013

SOUZA, M. L. de. Mudar a cidade: uma introdução crítica ao planejamento e à gestão urbanos. 8. Ed. Rio de Janeiro: Bertrand Brasil, 2011.

PANIZZI, W.; ROVATTI, J. F. (Org.). Estudos urbanos: Porto Alegre e seu planejamento. Porto Alegre: Ed. UFRGS; Prefeitura Municipal de Porto Alegre, 1993.

TRICART, J. Ecodinâmica. Rio de Janeiro: FIBGE/Supren, 1977.

YURI, S.; ANGELA, L. F. A dimensão urbana da natureza: considerações sobre a história ambiental. Revista Bibliográfica de Geografía Y Ciencias Sociales, Barcelona, v. XVIII, n. 1039, 30 ago. 2013. 